\title{
$\begin{array}{ll} & \text { Preprints are preliminary reports that have not undergone peer review. } \\ \text { Research Square } & \text { They should not be considered conclusive, used to inform clinical practice, }\end{array}$
}

\section{Grain Dispersal Mechanism In Cereals Arose From a Genome Duplication Followed By Changes in Spatial Expression of Genes Involved In Pollen Development}

\author{
Arthur Cross \\ University of Melbourne Faculty of Veterinary and Agricultural Sciences \\ John Baijun \\ University of Melbourne Faculty of Veterinary and Agricultural Sciences \\ Robbie Waugh \\ University of Dundee
}

Agnieszka Golicz

University of Giessen: Justus Liebig Universitat Giessen

Mohammad Pourkheirandish ( $\square$ mohammad.p@unimelb.edu.au )

The University of Melbourne_School of Agriculture and Food https://orcid.org/0000-0003-4337-3600

\section{Research Article}

Keywords: brittle rachis, domestication, co-expression analysis, meiosis, cell wall, evolution

Posted Date: November 2nd, 2021

DOI: https://doi.org/10.21203/rs.3.rs-947707/v1

License: (c) (i) This work is licensed under a Creative Commons Attribution 4.0 International License. Read Full License

Version of Record: A version of this preprint was published at Theoretical and Applied Genetics on February 22nd, 2022. See the published version at https://doi.org/10.1007/s00122-022-04029-8. 


\section{Abstract}

One of the most critical events in the process of cereal domestication was the loss of the natural mode of grain dispersal. Grain dispersal in barley is controlled by two major genes, Btr 1 and $B t r 2$, which affect the thickness of cell walls around the disarticulation zone. The barley genome also encodes Btr1-like and Btr2-like genes, which have been shown to be the ancestral copies. While Btr and Btr-like genes are nonredundant, the biological function of Btr-like genes is unknown. We explored the potential biological role of the Btr-like genes by surveying their expression profile across 212 publicly available transcriptome datasets representing diverse organs, developmental stages and stress conditions. We found that Btr1-like and Btr2-like are expressed exclusively in immature anther samples throughout Prophase I of meiosis within the meiocyte. The similar and restricted expression profile of these two genes suggests they are involved in a common biological function. Further analysis revealed 141 genes co-expressed with Btr1-like and 122 genes co-expressed with Btr2-like, with 105 genes in common, supporting Btr-like genes involvement in a shared molecular pathway. We hypothesize that the Btr-like genes play a crucial role in pollen development by facilitating the formation of the callose wall around the meiocyte or in the secretion of callase by the tapetum. Our data suggest that Btrgenes retained an ancestral function in cell wall modification and gained a new role in grain dispersal due to changes in their spatial expression becoming spike specific after gene-duplication.

\section{Key Message}

Grain disarticulation in wild progenitor of wheat and barley evolved through a local duplication event followed by neo-functionalization resulting from changes in location of gene expression.

\section{Introduction}

Barley was among the earliest cereal crops domesticated by humans (Harlan and Zohary 1966). The process of (artificial) selection on target traits for agriculture from the wild progenitor (Hordeum vulgare L. ssp. spontaneum) occurred in the Fertile Crescent 9,000 to 12,000 years ago (Tanno and Willcox 2006). The most discernible difference between the wild and the domesticated form of barley is the loss of the natural grain dispersal mechanism in the domesticated type (Pourkheirandish et al. 2015).

Grains from wild cereals progressively break off along the spike and scatter on the ground as the plant senesces and dries. In wild barley, grain dispersal occurs due to the development of a structural weak-point at each node of the central floral shaft (rachis). The weak-point presents as constriction grooves that allow mature grains to disarticulate from the rachis when a minimal external force is applied (Ubisch 1915). The functional trait of grain dispersal in wild barley is called 'brittle rachis'. Cultivated barley does not appear to possess these constriction grooves, preventing the separation of grain from the shaft, which results in the loss of the natural grain dispersal system allowing for easier harvest. Currently, two identified genes have been associated with the non-brittle rachis characteristics in all domesticated strains of barley, the Nonbrittle rachis 1 (btr1) and Non-brittle rachis 2 (btr2) genes (Pourkheirandish et al. 2015).

These two genes behave in a complementary dominant manner. Plants which carry a non-functional allele of either of these genes (btr1Btr2 or Btr1btr2) are referred to as the non-brittle rachis type. This type has a durable spike at full maturity. While the specific molecular functions of Btr1 and Btr2 are unknown, an analysis of the secondary structure of the proteins predicts that they work in tandem as a receptor-ligand pair regulating the thickness of the cell wall (Pourkheirandish et al. 2015). Genomic and experimental analysis has revealed their precise location, tightly linked as a head-to-head gene pair on chromosome $3 \mathrm{H}$, located $88 \mathrm{~kb}$ apart in the genome of the cultivar (cv.) Morex (Pourkheirandish et al. 2015). Despite their being crucial to the development of cultivated barley, no commercial cultivars carrying both mutant alleles of the Btr genes have yet been reported, suggesting there is no advantage to having both genes in the mutant form (Pourkheirandish et al. 2015). However, natural recombination between Btr1 and Btr2 have been discovered within agriocrithon barley (an ancestral six-row form of barley with a brittle rachis), demonstrating the possibility of genetic exchange between these two loci (Pourkheirandish et al. 2018). The presence of both btr1 and btr2 mutants in natural diverse barley populations demonstrates that two independent selection events have likely been made by ancient farmers during barley domestication.

Analysis of the barley genome led to the discovery of homologues of Btr1 and Btr2 based on the DNA sequence similarity. These genes have been named Btr1-like and Btr2-like. The physical proximity of the Btr gene pair and the Btr-like genes on chromosome $3 \mathrm{H}$ and their similar orientation suggests they arose by a local block duplication. Btr1 and Btr1-like, as well as Btr2 and Btr2-like have similar sequence, but no functional redundancy since the loss of function of Btr genes is not compensated by their functional Btr-like homologues (Pourkheirandish et al. 2015). Preliminary studies showed Btr expression in the rachis primordia with very limited information about $B$ tr-like gene expression profiles. A study of Einkorn wheat on the corresponding gene location revealed a highly similar gene organization in the wheat genome (Pourkheirandish et al. 2017). Phylogenetic analysis of both the Btr and Btr-like genes shows that the Btr-like genes are ancestral to the Btrgenes (Zeng et al. 2020). The block duplication therefore occurred before the separation of wheat and barley more than 5 million years ago and their conservation hints at a crucial function in both wheat and barley (Li et al. 2006b; Pourkheirandish et al. 2017). 
The objective of this study was to determine the possible molecular function of Btr1-like and Btr2-like in barley in order to infer the ancestral functions of Btr1 and Btr2. Gene expression profiling across over two hundred RNA-seq samples showed that the Btr-like gene pair is expressed specifically in immature anthers. Analysis of their co-expression partners suggested roles in cell wall modification and pollen development. Together the results indicate that the Btr 1 and $B t r 2$ genes retained an ancestral function in cell wall modification and gained a new role in grain dispersal due to changes in spatial gene expression post gene-duplication.

\section{Materials And Methods}

\section{Transcriptome sample selection}

We tested the transcription pattern of Btr1-like and Btr2-like in a variety of samples to determine their spatio-temporal expression. A total of 212 barley transcriptome datasets were obtained from five bioprojects selected for this analysis. Bioprojects were selected to cover a wide range of tissues and developmental time points. The tissue types found in these bioprojects cover four general plant growth stages: germination, vegetative, reproductive (non-sexual organs) and reproductive (sexual organs).

The chosen projects, listed by their NCBI accession codes, were PRJEB14349 (16 Developmental Stages, 96 samples), PRJNA558196 (Meiosis, 18 samples), PRJNA496380 (Seed Germination, 60 samples), PRJEB12540 (Drought Stress, 28 samples) and PRJNA324116 (Heat Stress, 10 samples) (Barakate et al. 2020; Cantalapiedra et al. 2017; Liew et al. 2020; Mascher 2019; Pacak et al. 2016). The 16 Developmental Stages project is the largest and the most comprehensive dataset used in this study, representing a range of tissues at different developmental stages. The Meiosis project includes reproductive male organs of anther and isolated meiocyte (pollen mother cell) transcriptomes and represents genes that are involved in reproduction. The Seed Germination project contains data of barley seeds, and includes tissues involved in germination. The Drought Stress and Heat Stress projects explored the gene expression profiles of barley under varying water and temperature stresses.

\section{Mapping reads and gene quantification}

The reference genome file, Barley Morex V2 pseudomolecules, was downloaded from The Leibniz Institute of Plant Genetics and Crop Plant Research (IPK). The RNA-Seq reads were aligned to the reference genome using HISAT2 V2.1.0 (Kim et al. 2019). The scripts are available from https://github.com/MohammadP2020/Honours-Btr-like. To quantify gene expression, read counts were normalized to Transcripts Per Million (TPM). Gene expression was quantified by TPMCalculator Version 0.0.3 (Vera Alvarez et al. 2019) using the Barley_Morex_V2_gene_annotation_PGSB.all.gtf annotation file. The TPM values for all genes in all samples were calculated.

\section{Co-expression Analysis}

RNA-Seq data were visualized using the heatmap tool maintained by the Broad Institute, Morpheus (https://software.broadinstitute.org/morpheus/). The imported file contained all 63,658 genes in the barley reference genome (Supplementary Data 1). Due to software memory restrictions, the number of genes in the table had to be reduced. Since the expression of Btr1-like and Btr2-like were highest at pachytene-diplotene in the meiocyte (more than 110 TPM for both Btr-like genes), any gene with a value below one TPM in that sample was removed. This adjustment removed 43,403 genes from the matrix, with 20,255 genes remaining within the dataset. This modification was sufficient for co-expression analysis in Morpheus using the 'Nearest Neighbours' tool and generating a heatmap.

\section{Sample evaluation and quality control}

Hierarchical clustering (1-Pearson's $r$ used as a measure of distance) was performed as a quality control test to confirm clustering of withinproject replicates and samples across projects. A dendrogram was generated using the inbuilt hierarchical clustering tool in Morpheus. Sample replicates that did not cluster together were removed from the analysis. The TPM values of replicates were then averaged to view how individual samples cluster together (Supplementary Data 2). The 'Nearest Neighbours' function in Morpheus was used to search for other genes with similar expression patterns to Btr1-like and Btr2-like using Pearson's correlation coefficient. Genes with a similar expression, deemed by a correlation coefficient of 0.95 or larger, were selected for further analysis.

\section{Functional Annotation using NCBI BLAST}

The coding sequences of all the genes that had 0.95 or higher correlation coefficient to the expression pattern of Btr7-like or Btr2-like were extracted from Barley_Morex_V2.cds.fa using the script named get.sample.seqs.sh in conjunction with get_seqs.py, both of which are available from https://github.com/MohammadP2020/Honours-Btr-like. The resultant fasta file containing the co-expressed genes was functionally annotated using Blast2GO Version 5.2.5 (Götz et al. 2008). BLAST was performed on the sequences using the public NCBI BLAST service. This step was executed using the blastx and the non-redundant (nr) database with the default settings. Mapping was based on two databases, Gene Ontology Association and Uniprot's ID-Mapping on 20 June 2020. Annotation was performed using the default parameters. InterProScan (IPS) 
was executed via the EMBL-EBI web server. The 'Combined Graphs' function was used to visualize the statistical information of the analysis. This analysis produced three graphs related to gene ontology (GO); biological process, molecular function and cellular component.

\section{Investigating potential barley-rice orthologues and homologues}

A local rice database was constructed using the "Make Blast Database" function available on Blast2GO with the default settings. This rice database contains the coding sequence of the Nipponbare/japonica subspecies of Oryza sativa, retrieved from the Genome Portal at Joint Genome Institute's Phytozome v13 Plant Genomics Resource (JGI) (Ouyang et al. 2007).

A BLAST search was performed against this local rice database using the fasta file of the co-expressed genes to identify potential homologous sequences. This step was executed using the blastn (-task blastn) using the e-value of $1 \mathrm{e}-3$ as a threshold. For genes that received multiple hits, only the top hit was retained. Alignment score was used as a measure of sequence length similarity. The equation used to calculate the alignment score is shown below.

Alignment score $=100 *$ (Alignment length / Length of barley gene)

An integrative approach combining sequence similarity and expression profiling was used for further functional annotation (Golicz et al. 2018). Gene pairs with a score $>60 \%$ were retained. The resulting list of genes then had their rice locus identifier recorded and then selected for further analysis by consulting the Rice Genome Annotation Project (RGAP) Version 7, where their expression profiles are available for viewing. The genes which showed an RNA-Seq Fragments Per Kilobase of transcript per Million mapped reads (FPKM) expression value higher than zero in the pre-emergence inflorescence were investigated. The pre-emergence inflorescence in rice was considered as the closest developmental stage to the anthers and meiocytes, where the expression of Btr-like genes was detected previously.

The rice genes that showed FPKM value larger than zero in the pre-emergence inflorescence were searched through funRiceGenes (https://funricegenes.github.io), a comprehensive database that contains functionally characterized rice genes and their related publications (Yao et al. 2017). Multiple sequence alignments were performed using online CLUSTAL multiple sequence alignment MUSCLE Version 3.8. The software calculated percentage identify through the generation of a 'Percent Identity Matrix'. Orthologous genes were also searched within a barley-rice genome zipper (Mayer et al. 2011).

\section{Results}

\section{Transcriptome sample selection}


Table 1

List of the RNA-Seq libraries used in this study.

\begin{tabular}{|c|c|c|c|c|}
\hline NCBI BioProject & Germination & Vegetative & $\begin{array}{l}\text { Reproductive } \\
\text { (Non-Sexual } \\
\text { Organs) }\end{array}$ & Reproductive (Sexual Organs) \\
\hline $\begin{array}{l}16 \text { Developmental } \\
\text { Stages } \\
\text { (PRJEB14349) }\end{array}$ & $\begin{array}{l}\text { Developing grain } \\
5 \text { days post anthesis } \\
15 \text { days post } \\
\text { anthesis } \\
\text { 4-day embryo }\end{array}$ & $\begin{array}{l}\text { Epidermis } \\
\text { Developed (4 } \\
\text { weeks) } \\
\text { Etiolated } \\
\text { Senescing } \\
\text { Etiolated } \\
\text { Seedling } \\
\text { Root } \\
\text { Young (from } \\
\text { seedling } \\
\text { Developed (4 } \\
\text { weeks) } \\
\text { Shoot } \\
\text { Young (from } \\
\text { seedlings) } \\
\text { Developed (4 } \\
\text { weeks) } \\
\text { Tiller }\end{array}$ & $\begin{array}{l}\text { Rachis } \\
\text { Lemma } \\
\text { Lodicule } \\
\text { Palea }\end{array}$ & $\begin{array}{l}\text { Inflorescence } \\
\text { Young developing }(5 \mathrm{~mm}) \\
\text { Developing }(10-15 \mathrm{~mm})\end{array}$ \\
\hline $\begin{array}{l}\text { Meiosis } \\
\text { (PRJNA558196) }\end{array}$ & & & & $\begin{array}{l}\text { Anther }(\mathrm{mm}) \\
\text { 0.3-0.4, 0.5-0.9, 1.0-1.2, 1.3-1.4 } \\
\text { Meiocyte } \\
\text { Pre-meiosis, Leptotene-Zygotene, Pachytene-Diplotene, } \\
\text { Metaphase-Tetrad }\end{array}$ \\
\hline $\begin{array}{l}\text { Seed Germination } \\
\text { (PRJNA496380) }\end{array}$ & $\begin{array}{l}\text { Scutellum } \\
\text { Oh, } 8 h, 16 h, 24 h, 32 h, \\
40 h, 48 h \\
\text { Plumule } \\
\text { Oh, } 8 h, 16 h, 24 h, 32 h, \\
40 h, 48 h \\
\text { Radicle } \\
\text { Oh, } 8 h, 16 h, 24 h, 32 h, \\
40 h, 48 h\end{array}$ & & & \\
\hline $\begin{array}{l}\text { Drought Stress } \\
\text { (PRJEB12540) }\end{array}$ & & $\begin{array}{l}\text { Leaf } \\
\text { Control } \\
\text { Mild drought } \\
\text { Severe drought }\end{array}$ & & $\begin{array}{l}\text { Inflorescence } \\
\text { Control } \\
\text { Mild drought } \\
\text { Severe drought }\end{array}$ \\
\hline
\end{tabular}




\begin{tabular}{|c|c|c|c|c|}
\hline NCBI BioProject & Germination & Vegetative & $\begin{array}{l}\text { Reproductive } \\
\text { (Non-Sexual } \\
\text { Organs) }\end{array}$ & Reproductive (Sexual Organs) \\
\hline Heat Stress & & Root & & \\
\hline \multirow[t]{5}{*}{ (PRJNA324116) } & & Control $\left(22.0^{\circ} \mathrm{C}\right)$ & & \\
\hline & & $\begin{array}{l}\text { Heat stress } \\
\left(35.5^{\circ} \mathrm{C}\right)\end{array}$ & & \\
\hline & & Shoot & & \\
\hline & & Control $\left(22.0^{\circ} \mathrm{C}\right)$ & & \\
\hline & & $\begin{array}{l}\text { Heat stress } \\
\left(35.5^{\circ} \mathrm{C}\right)\end{array}$ & & \\
\hline
\end{tabular}

Barley RNA-Seq datasets shown in Table 1 were downloaded from NCBI and aligned to the barley reference genome using HISAT2. Alignments were of high quality, with the average overall alignment rate across all samples being $85.98 \%$ (Supplementary Data 3). The Btr-like genes were of primary interest in this study. While the expression data that we analysed is from different barley cultivars including cvs. Morex, cv. Golden Promise, cv. Scarlett, and Spanish landrace SBCC073, we utilized the reference genome and the annotation from cv. Morex.

The Morex annotation possessed two copies of the Btr1-like gene and three of the Btr2-like gene, all of which are potentially functional. These all exist within one Mbp of each other on chromosome 3H (Figure 1A). Btr1 and Btr1-like-a and Btr1-like-b1, share $58.55 \%$ and $59.18 \%$ amino acid identity (Figure 1B). Btr2 and Btr2-like-a, Btr2-like-b1, Btr2-like-b2, share $57.81 \%, 62.43 \%$ and $62.56 \%$ amino acid identity (Fig. 1C). According to the phylogenetic trees constructed based on amino acid alignment, Btr1-like gene copies are more closely related to each other than Btr1 (Figure 2A). Similarly, Btr2-like gene copies are more closely related than Btr2 (Figure 2B).

Gene IDs refer to the identities given in the V2 pseudomolecules annotation excluding the BTR2 because the cv. Morex does not have a functional BTR2 protein. The OUH602 BTR2 gene was used instead because its functionality has been documented.

High sample quality is indicated by hierarchical clustering of similar tissue types across projects (data not shown). However, in the Drought project the Spanish landrace replicates 'SBCC073 leaf in mild drought and heat stress' did not cluster together and were therefore removed from further analysis. Since samples in the germination project had exceptionally high degree of similarity, the decision was made to keep only $8 \mathrm{~h}$ samples and the $48 \mathrm{~h}$ samples as representative and remove the $0 \mathrm{~h}, 16 \mathrm{~h}, 24 \mathrm{~h}, 32 \mathrm{~h}$ and $40 \mathrm{~h}$ samples. The $8 \mathrm{~h}$ samples were selected over the $0 \mathrm{~h}$ samples because they had three replicates, consistent with the number $48 \mathrm{~h}$ possessed. Once the above revisions were made, the TPMs values across replicates were averaged.

All Btr-like genes displayed similar expression patterns and their co-expression patterns are highly correlated, with above 0.95 Pearson's correlation (Table 2). These genes show highly specific expression within the anther (zero to 145 TPM) and meiocyte (25 to 244 TPM) of barley undergoing meiosis (Table 3). No expression was detected for either of the Btr-like genes in any other organs used in this study (expression threshold of 1 TPM). The only exception to this specific expression pattern was low-level expression for the Btr1-like genes in the root samples of the Heat Stress project with maximum expression of 7.15 TPM (Btr1-like-a in root under $35^{\circ} \mathrm{C}$ heat stress, Table 3). The expression patterns during meiosis of these copies are presented in Table 3 (expression across all samples can be found in Supplementary Data 1). The highest expression levels for all genes were present in the meiocyte at the pachytene diplotene stage of meiosis (Table 3). We also confirmed the stage specific expression patterns with the EoRNA database which stores expression data for 843 samples using barley gene reference transcript dataset (BaRT) and barley genome annotation V1 as a reference (Milne et al. 2021) (Supplementary Data 4).

The pair with the highest expression was selected for further analysis (Btr1-like-a and Btr2-like-a). The corresponding expression patterns of this pair during meiosis are shown graphically in Figure 3.

Table 2

Pearson's correlation between the copies of Btr1-like and Btr2-like

\begin{tabular}{|llllll|}
\hline Barley Gene Name & Btr1-like-a & Btr1-like-b1 & Btr2-like-a & Btr2-like-b1 & Btr2-like-b2 \\
\hline Btr1-like-a & 1 & 0.99 & 0.99 & 1 & 0.99 \\
\hline Btr1-like-b1 & 0.99 & 1 & 0.97 & 0.99 & 1 \\
\hline Btr2-like-a & 0.99 & 0.97 & 1 & 0.99 & 0.96 \\
\hline Btr2-like-b1 & 1 & 0.99 & 0.99 & 1 & 0.98 \\
\hline Btr2-like-b2 & 0.99 & 1 & 0.96 & 0.98 & 1 \\
\hline
\end{tabular}

Page 6/18 
Table 3

TPM values for copies of the Btr-like genes located on chromosome $3 \mathrm{H}$ in the anther and meiocyte during the early stages of meiosis and the outlier root sample from the Heat Stress project. Barley Gene ID: Barley sequence name "HORVU.MOREX.r2.". Lep-Zyg: Leptotene-Zygotene, Pach-Dip: Pachytene-Diplotene, Met-Tet: Metaphase-Tetrad.

\begin{tabular}{|c|c|c|c|c|c|c|c|c|c|}
\hline \multirow[t]{2}{*}{ Barley Gene ID (Morex) } & \multirow[t]{2}{*}{ Gene Name } & \multicolumn{4}{|l|}{ Anther } & \multicolumn{2}{|c|}{ Meiocyte } & \multicolumn{2}{|c|}{$\operatorname{Root}\left({ }^{\circ} \mathrm{C}\right)$} \\
\hline & & Pre-meiosis & Lep-Zyg & Pach-Dip & Met-Tet & $\begin{array}{l}\text { Lep- } \\
\text { Zyg }\end{array}$ & Pach-Dip & 22 & 35.5 \\
\hline 3HG0195460 & Btr1-like-a & 11.87 & 40.75 & 145.34 & 115.23 & 83.01 & 244.05 & 4.58 & 7.15 \\
\hline 3HG0195170 & Btr1-like-b1 & 6.98 & 26.26 & 101.73 & 77.54 & 57.12 & 161.87 & 1.33 & 2.37 \\
\hline 3HG0195480 & Btr2-like-a & 0 & 7.20 & 63.61 & 57.40 & 24.55 & 112.70 & 0 & 0.08 \\
\hline 3HG0195160 & Btr2-like-b1 & 0.95 & 9.19 & 20.41 & 16.30 & 16.61 & 36.04 & 0.96 & 2.98 \\
\hline 3HG0195470 & Btr2-like-b2 & 0.17 & 1.56 & 3.70 & 2.53 & 3.43 & 7.02 & 0.08 & 0.29 \\
\hline
\end{tabular}

Co-expression Analysis

We identified 141 genes correlated to the Btr1-like transcription pattern, and 122 genes correlated to the Btr2-like transcription pattern (Pearson's correlation $\geq 0.95$ ). Further analysis showed that 105 genes were correlated to both Btr-like genes (Figure 4), suggesting that Btr1-like and Btr2like are involved in the same molecular process. Additionally, the Pearson's correlation between Btr1-like and Btr2-like was 0.99 (Table 3).

\section{Functional Annotation using Blast2GO}

The function of the Btr-like genes was inferred by analysing the molecular, cellular, and biological function of genes that have similar expression patterns. The Blast2GO analysis assigned 71 genes with $\mathrm{GO}$ annotations for genes co-expressed with Btr1-like and 55 genes co-expressed with Btr2-like. The breakdown of the GO codes for the 'biological process' category are shown below (Figure 5).

The 'reproductive process' category was especially interesting because of high expression levels of the Btr-like genes in meiocyte and anther. A total of five genes were assigned to the reproductive process GO code (G0:0022414). Four genes were annotated with GO from the correlated genes of Btr1-like and Btr2-like, three of which were co-expressed with both Btr1-like and Btr2-like(Table 4).

Table 4

Genes co-expressed with Btr1-like and Btr2-like that possess GO codes associated with the 'reproductive process' category. Barley Gene ID: Barley sequence name "HORVU.MOREX.r2.".

Barley Gene ID Go code Co-

expressed

$(>0.95)$

2HG0086890.1 reciprocal meiotic recombination (G0:0007131), meiosis I (G0:0007127), meiotic nuclear division (GO:0140013), meiosis I cell cycle (GO:0061982), meiotic DNA double-strand break formation (GO:0042138), meiotic cell cycle process (GO:1903046), meiotic cell cycle (G0:0051321)

Btr1-like and Btr2like

2HG0109560.1 plant ovule development (G0:0048481), plant-type ovary development (G0:0035670), carpel development (G0:0048440), gynoecium development (GO:0048467), floral organ development (G0:0048437), floral whorl development (GO:0048438), flower development (G0:0009908), reproductive shoot system development (GO:0090567), reproductive structure development (G0:0048608), developmental process involved in reproduction (GO:0003006)

6HG0456990.1 anther development (GO:0048653), stamen development (G0:0048443), androecium development (GO:0048466), floral whorl (G0:0048438), floral organ development (GO: 0048437), flower development (GO:0009908), reproductive shoot system development (GO:0090567), reproductive structure development (G0:0048608), developmental process involved in reproduction (G0:0003006)

1HG0041780.1 seed development (G0:0048316), fruit development (G0:0010154), reproductive structure development (G0:0048608), developmental process involved in reproduction (G0:0003006)

Btr1-like and Btr2like anther dehiscence (G0:0009901), anther development (GO:0048653), stamen development (G0:0048443), androecium development (G0:0048466), floral whorl development (G0:0048438), floral organ development (GO: 0048437), flower development (G0:0009908), reproductive shoot system development (G0:0090567), fruit dehiscence (G0:0010047), reproductive structure development (GO:0048608), dehiscence (G0:009900), developmental process involved in reproduction (G0:0003006), multicellular organismal reproductive process (G0:0048609)

\section{Investigating potential barley-rice orthologues}

While some of the co-expressed genes were annotated as associated with reproduction, the gene ontology analysis did not provide enough information to determine the functions for the majority of the genes (Table 4). The potential functions the 158 barley genes (Figure 4 ) were 
investigated by comparing the gene sequences to annotated genes in the rice genome. Potential rice orthologues of barley genes were identified by selecting genes that met the following criteria (1) maximum E-value of 1e-3 in BLASTN comparisons (2) alignment score above 60\%, (3) observable expression in pre-emergence inflorescence $(F P K M>0)(4)$ detailed functional characterization described in the funRiceGenes database. A total of 19 genes met all the criteria, 16 of which were associated with Btr1-like, 10 with Btr2-like, and seven with both (Table 5). A full list of 55 genes fitting criteria (1) to (3) can be viewed in Supplementary Data 5.

Table 5

Function of the potential rice orthologue of co-expressed genes of both Btr1-like and Btr2-like, only Btr1-like and only Btr2-like. Barley Gene ID: Barley sequence name "HORVU.MOREX.r2.". Rice Gene ID: Locus ID of matched rice gene "LOC_Os". Key message of rice genes retrieved from https://funricegenes.github.io on 05/10/20.

\begin{tabular}{|c|c|c|c|c|c|c|}
\hline Barley Gene ID & $\begin{array}{l}\text { Rice Gene } \\
\text { ID (MSU) }\end{array}$ & $\stackrel{e}{\text { Value }}$ & Rice gene & Molecular function (rice gene) & $\begin{array}{l}\text { Correlation } \\
\text { (Btr1-like) }\end{array}$ & $\begin{array}{l}\text { Correlation } \\
\text { (Btr2-like) }\end{array}$ \\
\hline 1HG0038070.1 & $10 \mathrm{~g} 36170.1$ & $\begin{array}{l}1.76 \mathrm{E}- \\
48\end{array}$ & OsLTP2.12 & lipid transfer protein & 0.95 & 0.95 \\
\hline 1HG0057890.1 & $05 g 39560.1$ & 0 & OsZIP5 & zinc transporter & 0.96 & 0.97 \\
\hline 2HG0109560.1 & $07 g 38410.1$ & $\begin{array}{l}5.16 \mathrm{E}- \\
109\end{array}$ & OsYABBY7 & Summary of YABBY family genes & 0.99 & 0.98 \\
\hline 3HG0222470.1 & $01 \mathrm{~g} 40630.1$ & 0 & $\angle O G$ & maintain meristem activity & 0.98 & 0.97 \\
\hline 4HG0324070.1 & $03 g 15880.1$ & 0 & OsCOI2 & jasmonate signal transduction & 0.96 & 0.95 \\
\hline 4HG0325010.1 & $03 g 15340.1$ & $\begin{array}{l}6.57 \mathrm{E}- \\
106\end{array}$ & UCL7 & uclacyanin-like protein family & 0.95 & 0.96 \\
\hline $6 \mathrm{HG} 0456990.1$ & $02 g 02820.1$ & 0 & $T D R$ & tapetum degeneration retardation & 0.98 & 0.96 \\
\hline 1HG0041780.1 & $\log 42550.1$ & 0 & ITPK5 & phytic acid biosynthesis & 0.96 & 0.93 \\
\hline 3HG0197830.1 & $07 g 28850.1$ & 0 & $\begin{array}{l}\text { AG018, } \\
\text { OsAGO18 }\end{array}$ & $\begin{array}{l}\text { male gametophyte development by small RNA- } \\
\text { mediated mechanism, virus resistance }\end{array}$ & 0.95 & 0.91 \\
\hline 3HG0256970.1 & $01 \mathrm{~g} 65790.1$ & 0 & OsPME7 & pectin modification, root elongation inhibition & 0.96 & 0.93 \\
\hline 4HG0289080.1 & $11 g 08200.1$ & $\begin{array}{l}3.15 \mathrm{E}- \\
52\end{array}$ & OsAsp1 & $\begin{array}{l}\text { Aspartic acid regulation, Nucellin programmed cell } \\
\text { death and meristematic development }\end{array}$ & 0.96 & 0.94 \\
\hline 4HG0343230.1 & 06g10990.1 & $\begin{array}{l}1.61 \mathrm{E}- \\
101\end{array}$ & S5(ORF3) & rice wide compatibility gene S5 & 0.96 & 0.92 \\
\hline 4HG0347150.1 & $03 g 01160.2$ & 0 & OsPUB50 & U-box-containing proteins & 0.95 & 0.93 \\
\hline 6HG0477800.1 & $09 g 26660.1$ & 0 & $\begin{array}{l}\text { OsrbohB, } \\
\text { Osrboh7 }\end{array}$ & ROS production & 0.95 & 0.94 \\
\hline $6 \mathrm{HG} 0498590.1$ & $02 g 44250.1$ & 0 & OsINP1 & Rice pollen aperture formation & 0.95 & 0.93 \\
\hline 7HG0586190.1 & 08g01410.1 & 0 & OsUGT2 & sugar transporter & 0.95 & 0.94 \\
\hline 7HG0622890.1 & $\log 25310$ & 0 & OsSPX3 & $\begin{array}{l}\text { Overexpression of OsSPX3 downregulates OsSPX5 } \\
\text { in shoots under Pi-sufficiency }\end{array}$ & 0.93 & 0.95 \\
\hline $5 \mathrm{HG} 0413550.1$ & $02 g 28870.1$ & 0 & OsPUB73 & Tapetum and exine abnormalities & 0.93 & 0.96 \\
\hline 2HG0132740.1 & $04 g 30470$ & 0 & OsPUB76 & Summary of U-BOX-containing proteins & 0.94 & 0.95 \\
\hline
\end{tabular}

Among the 19 genes shown in Table 5, there were six well-described genes that are involved in pollen or reproductive tissue development in rice. These were TDR, OsINP1, OsPUB73, OsAsp1, ITPK5, OsYABBY7. Multiple sequence alignment compared the amino acid sequence between the rice genes and their prospective orthologous/homologous sequence in barley and wheat are presented in Table 6 . The full sequence alignments between barley, rice and wheat can be found in Supplementary Data 6. Investigation of OsAsp1 revealed two homologues in barley, for which a multiple sequence alignment and percentage similarity between them can be viewed in Supplementary Data 7.

Sorghum and Brachypodium orthologues were found using synteny maps contracted using the genome zipper approach (Table 6). This analysis revealed potential orthologues of Brachypodium for TDR and OsINP1, while potential orthologues of sorghum were identified for TDR, OsINP1 and ITPK5 (Mayer et al. 2011). 
Table 6

Amino acid sequence identity of potential rice orthologues of co-expressed genes of Btr1-like and Btr2-like with potential orthologues from wheat, Brachypodium and sorghum. Barley Gene ID: Barley sequence name "HORVU.MOREX.r2.". Brachypodium Gene ID: "Bradi". Sorghum

\begin{tabular}{|c|c|c|c|c|c|c|c|c|}
\hline Barley Gene ID & $\begin{array}{l}\text { Rice gene } \\
\text { name }\end{array}$ & $\begin{array}{l}\text { Barley- } \\
\text { rice } \\
\text { amino } \\
\text { acid } \\
\text { identity } \\
(\%)\end{array}$ & $\begin{array}{l}\text { Wheat gene } \\
\text { accession } \\
\text { code (NCBI) }\end{array}$ & $\begin{array}{l}\text { Barley- } \\
\text { wheat } \\
\text { amino } \\
\text { acid } \\
\text { identity } \\
\text { (\%) }\end{array}$ & $\begin{array}{l}\text { Brachypodium } \\
\text { Gene ID }\end{array}$ & $\begin{array}{l}\text { Sorghum } \\
\text { Gene ID }\end{array}$ & $\begin{array}{l}\text { Molecular } \\
\text { function in } \\
\text { rice }\end{array}$ & $\begin{array}{l}\text { Biological } \\
\text { function in rice }\end{array}$ \\
\hline 2HG0109560.1 & OsYABBY7 & 66.67 & KAF7015187.1 & 94.51 & - & - & $\begin{array}{l}\text { Transcription } \\
\text { factor }\end{array}$ & $\begin{array}{l}\text { Morphogenesis, } \\
\text { ovule } \\
\text { development }\end{array}$ \\
\hline $6 \mathrm{HG} 0456990.1$ & $T D R$ & 64.88 & KAF7088250.1 & 92.41 & $3 g 01901.1$ & 04g001650.1 & $\begin{array}{l}\text { Transcription } \\
\text { factor }\end{array}$ & $\begin{array}{l}\text { Pollen } \\
\text { development, } \\
\text { cell death }\end{array}$ \\
\hline 1HG0041780.1 & ITPK5 & 78.36 & KAF6983924.1 & 97.41 & - & $01 \mathrm{~g} 028090$ & Kinase & $\begin{array}{l}\text { Drought } \\
\text { tolerance }\end{array}$ \\
\hline 4HG0289080.1 & OsAsp1 & 48.55 & KAF7052952.1 & 85.84 & - & - & $\begin{array}{l}\text { Aspartic acid } \\
\text { protease }\end{array}$ & $\begin{array}{l}\text { Programmed } \\
\text { cell death }\end{array}$ \\
\hline 6HG0498590.1 & OsINP1 & 85.10 & KAF7079703.1 & 96.28 & $3 g 50820.1$ & $04 g 032730.1$ & Unknown & $\begin{array}{l}\text { Morphogenesis, } \\
\text { pollen aperture } \\
\text { development }\end{array}$ \\
\hline 5HG0413550.1 & OsPUB73 & 47.28 & KAF7060109.1 & 88.51 & - & - & $\begin{array}{l}\text { Ubiquitin } \\
\text { ligase }\end{array}$ & $\begin{array}{l}\text { Programmed } \\
\text { cell death in } \\
\text { anther }\end{array}$ \\
\hline
\end{tabular}

\section{Discussion}

\section{The brittle rachis is a unique mechanism evolved in Triticeae tribe via a gene duplication}

Wild barley possesses a natural grain dispersal mechanism called the brittle rachis, which is governed by the presence of two tightly linked genes named Btr1 and Btr2 (Pourkheirandish et al. 2015). These genes are integral to the formation of the separation zone for the disarticulation of mature grain from the rachis. This separation zone presents due to the thinning of cell walls along the separation zone. The Btr1 and Btr2 genes are only found within some members of the Triticeae tribe including wheat and rye (Zeng et al. 2020). The presence of Btr1 and Btr2 correlates well with the brittle rachis characteristic (Sakuma et al. 2011). The unique separation mechanism (brittle rachis), and exclusive nature of gene sequences suggest that the Btr1 and Btr2 genes evolved in Triticeae which ultimately resulted in the development of a new dispersal mechanism. This hypothesis is further supported by the existence of duplicated copies of Btr1 and Btr2 with high sequence similarity in the barley genome known as Btr1-like and Btr2-like. Preliminary analysis has indicated that these Btr-like genes are not functionally redundant with Btr1 and Btr2. A functional Btr1-like gene cannot compensate the loss of function at the btr1 locus and similarly the loss of function of the btr2 locus cannot be compensated by a functional Btr2-like gene (Pourkheirandish et al. 2015). The Btr1-like and Btr2-like genes are thought to be the ancestral copies, with phylogenetic analysis showing that genes sharing homology with the Btr-like are found throughout the Poaceae family. In contrast, the Btr1 and Btr2 were limited to the Triticeae tribe (Zeng et al. 2020). Here, a bioinformatics approach was adopted to uncover the potential role of the Btr-like genes that may then shed light on the evolution and molecular function of Btr1 and Btr2.

\section{The Btr-like genes are exclusively expressed in plant reproductive organs}

A comprehensive analysis of barley transcripts revealed a highly specific expression pattern of the Btr-like genes. They are both exclusively expressed throughout the early meiotic stages of pollen development, indicating that they perform a crucial biological role in the reproductive process in barley. Additionally, the Btr1-like and Btr2-like genes have a synchronous expression pattern that supports their involvement in related biological processes. The expression of the Btr2 gene has been detected in cells at the rachis node during spike development at early white anther stage (Pourkheirandish et al. 2015). The immature spike in this stage is around 3-5 mm in length. The early white anther stage in spike coincides with the meiosis stage within the anthers. This suggests that Btrand Btr-like genes are expressed at a similar stage. However, the expression location differentiates the Btr2 expressed at rachis node) from the Btr-like genes (expressed within anthers), suggesting they have different biological roles within barley. For Btrgenes, the outcome is rachis disarticulation, which occurs during spike maturity much later than the Btr loci expression. This suggests that BTR proteins were required to create a separation zone during spike development that can break at the later stage. The Btr-like transcripts are exclusively found in anthers, but it is yet to be determined if their biological function is immediately pronounced at the same stage as their expression, or much later akin to the Btrgenes. The co-expression pattern of Btr1-like and Btr2-like genes supports a possible receptor-ligand pair relationship similar to that hypothesized for the BTR1 and BTR2 proteins (Pourkheirandish et al. 2015). 
It is tempting to speculate that the Btr1-like and Btr2-like unit was duplicated and then the copies functionally diverged to express in a different organ at a similar time (stage) with similar molecular function resulting in the Btr genes (Zeng et al. 2020).

Considering the above hypothesis, any information regarding the molecular function of Btr-like genes will be helpful to determine the molecular function of the brittle rachis. The highly specific expression patterns and homology of co-expression partners to known rice genes were used to infer biological processes of Btr1-like and Btr2-like.

\section{The biological function of Btr1-like and Btr2-like based on the co-expressed genes}

Rice is the best model crop in monocots possessing a detailed annotated genome. It has a relatively close relationship with barley, diverging from a common ancestor 50 million years ago (Middleton et al. 2014). The biological function of the genes co-expressed with Btr1-like and Btr2like was investigated using homologues in rice. There were six well-described genes in rice, where the barley putative orthologues were coexpressed with Btr-like and appeared to be involved in a similar biological process within pollen or reproductive tissue development.

Out of 158 genes co-expressed with at least one of the Btr1-like and Btr2-like in barley, 55 met our criteria for matches in the rice genome (Supplementary Data 5) and 19 had entries in the funRiceGenes database. Six were found to have well characterized functions in reproduction, which allows us to make inferences on the overall biological function of the Btr-like genes. These rice genes are named TDR (TAPETUM DEGENERATION RETARDATION), OsYABBY7(Oryza sativa YABBY 7), OsPUB73 (Oryza sativa PLANT UBIQUITIN-BOX 73), OsINP1 (Oryza sativa INAPERTURATE POLLEN 1), ITPK5 (INOSITOL 1,3,4-TRISPHOSPHATE 5/6-KINASE), and OsAsp1 (Oryza sativa ASPARTIC PROTEASE 1). Here we tried to speculate the function of Btr-like genes based on their molecular partners with similar expression patterns.

The TDR protein is a putative basic helix loop helix (bHLH) transcription factor ( $\mathrm{Li}$ et al. 2006a). It is preferentially expressed in the innermost layer of the anther (the tapetum) in rice. The tapetum is in direct contact with the developing pollen. Expression of TDR is specific to the anther and begins early in meiosis and peaks at the young microspore stage that is similar to the barley Btr-like genes demonstrated in this study. Naturally, in rice, the tapetum is almost completely degenerated by the vacuolated pollen stage allowing pollen the space to develop to maturity. However, in the loss of function mutation $(t d r)$ the tapetum does not degenerate as in the wild-type, swelling and destroying the meiocytes in the process. TDR silencing appears to be linked to the retardation of programmed cell death in the tapetum, meiocyte abortion and pollen wall abnormalities (Li et al. 2006a; Zhang et al. 2008). The most striking morphological defect is the delayed degeneration of the tapetum and results in complete male sterility. The pollen wall abnormalities have also been further investigated, revealing that these defects occurred after forming the primexine layer (micro-fibular matrix that forms the mould for the pollen wall deposition) by microspores (Blackmore and Barnes 1985; Echlin and Godwin 1968; Zhang et al. 2008). Barley has a prospective orthologue of TDR within the candidate gene list. Additionally, the barley orthologue was one of the genes identified in BLAST2GO analysis with the GO code for anther development. Multiple sequence alignment of the pair revealed that barley and rice TDR share amino acid sequence identity of $64.88 \%$. The expression patterns of rice $T D R$ and the barley orthologue temporally mirror each other. Since TDR is primarily expressed in the tapetum and the barley orthologue expressed in the meiocyte sample, this finding indicates that tapetal tissue was likely included in the sample (the membrane of the 'meiocyte bag') (Barakate et al. 2020). Rice TDR is located on chromosome 2, in syntenic position with the barley orthologue located on chromosome 3H (Mayer et al. 2011). Moreover, TDR has orthologous sequence not only in barley but Brachypodium and sorghum as well (Bradi3g01901.1 and Sb04g001650.1). This indicates that the gene is well conserved across monocots and, therefore likely has a conserved and crucial function as demonstrated in rice.

The OsYABBY7 protein is part of the YABBY gene family; the zinc finger transcription factor family, which has been known to play important biological roles in morphogenesis, growth, and development (Zhao et al. 2020). However, real-time PCR expression analysis of the YABBY genes in rice revealed that $O S Y A B B Y 7$ has a significantly lower-level but more targeted expression than the other $Y A B B Y$ genes (Toriba et al. 2007). $O S Y A B B Y 7$ is specifically expressed in the reproductive organs of flowers whereas the other OsYABBY genes have more general expression across all inflorescence structures and other meristematic tissues. Barley has a prospective orthologue of $O s Y A B B Y 7$ within the candidate gene list and the barley expression levels seen in our data strongly support similar expression patterns to rice. The barley orthologue was also identified within the BLAST2GO analysis with the GO code for plant ovule development. Multiple sequence alignment of these sequences revealed an amino acid sequence identity of $66.67 \%$. This gene is not well studied and would be a good candidate for further research.

The rice protein OsPUB73 was first identified with the U-box domain and putative function as an E3 ubiquitin ligase (Zeng et al. 2008). This protein domain has been linked with regulating programmed cell death signalling (Zeng et al. 2008). However, the context in which OsPUB73 has been expressed and the biological pathway it is involved in has only recently been investigated. It has shown high expression in the anther throughout the early stages of meiosis. Gene silencing of OSPUB73 in rice revealed reduced pollen fertility, incomplete tapetum degeneration/cell death and pollen exine abnormalities (Chen et al. 2019). The best match to rice OsPUB73 gene in barley genome is the candidate gene found in the current co-expression study and the multiple sequence alignment revealed the genes share a $47.28 \%$ amino acid sequence identity. The expression pattern of the putative barley orthologue is consistent with that of the rice gene. 
While both TDR and OSPUB73 are important for the development of fertile pollen neither of these genes prevents the meiotic process from occurring. The meiocytes in both mutant variants ( $t d r$ and ospub73) reach the tetrad stage without any obvious irregularities despite both genes being expressed well before the tetrad stage. While both genes cause similar abnormalities when defective, comparative co-expression analysis between mutant variants ospub73 and $t d r$ indicate that these genes could function in independent molecular pathways in rice (Chen et al. 2019). It is also possible that OsPUB73 is part of the same functional process as TDR but exists further downstream and does not affect the regulation of as many genes. Based on the co-expression, one can hypothesize that Btr-like genes are also involved in pollen cell wall development during the meiosis stage.

The putative function of OsINP1 is unknown, but its role in overall biological processes has been described in a rice gene knockout experiment (Zhang et al. 2020). Expression of OsINP1 is present in meiocytes in rice from the meiocyte stage to the free microspore stage (Zhang et al. 2020). Stained confocal microscopy revealed OsINP1 is localized to distal poles of the tetrad. Areas with high concentration marks points of depleted pollen precursor deposition, which appears to only occur at the position of the pollen aperture development. Pollen apertures are small openings on the pollen surface that allow the pollen tube to emerge from inside the pollen during fertilization (Edlund et al. 2004). It was demonstrated that while a mutation to OsINP1 does not affect the development of anthers and pollen grains, the aperture in mature pollen grains is absent in mutants. This prevents the emergence of the pollen tube, resulting in male sterility. Barley has a prospective orthologue of OsINP1 within the candidate gene list. The expression levels of the barley gene seen within this analysis are consistent with the function of Os/NP1 seen in rice. Multiple sequence alignment analysis of Os/NP1 and its potential barley orthologue reveal an $85.10 \%$ amino acid sequence identity. This gene is well conserved and has been identified in the barley-rice zipper genome synteny model, and Brachypodium and sorghum (Mayer et al. 2011).

The gene ITPK5 is a part of the ITPK gene family first uncovered in $A$. thaliana. This gene family appears to be exceptionally well conserved across monocot and dicot species. The ITPK gene family encodes a putative inositol 1,3,4-trisphosphate 5/6-kinase which is involved in polyphosphate biosynthesis and is part of the broader ATP-grasp proteins (Fawaz et al. 2011). Detailed studies in rice have been undertaken on the homologue ITPK2, which has been linked to response to drought tolerance. An expression comparison between ITPK genes present within rice (ITPK1-6) indicated that ITPK5 showed the highest expression within the endosperm, 7 and 14 days after pollination (Du et al. 2011). The expression analysis of the barley orthologue also shows expression in the developing grain (consistent with the endosperm), much like the rice orthologue. However, the barley orthologue exhibits an increased expression level during the early stages of meiosis that is not observed in the rice orthologue. GO codes associated with potential barley orthologue ITPK5 indicate it is involved in seed development. The difference in expression from the rice ITPK5 to the barley orthologue suggests that it may have additional biological function in barley. Multiple sequence alignment analysis of ITPK5 and its barley counterpart reveal a $78.36 \%$ amino acid sequence identity and it is located within the synteny model for sorghum (Mayer et al. 2011).

OsAsp 1 appears to be a homologue of a barley gene within the candidate gene list. This gene's molecular function is to produce an aspartic acid protease (Bi et al. 2005). This is a proteolytic enzyme that breaks down proteins that function optimally in acidic environments (Cao et al. 2019). It is known to be associated with meristematic activity and has been linked to various reproductive tissues: nucellus, embryos, ovary walls and the coleoptiles of immature seeds. Previous studies have indicated that this gene was more specifically involved in programmed cell death, however this has been disputed (Bi et al. 2005; Chen and Foolad 1997). There appear to be two homologues of OsAsp1 in barley, one is the barley 'nucellin' gene, the other is the gene on our candidate list that we will term nucellin-like. Multiple sequence alignment analysis of OsAsp 1, nucellin and nucellin-like proteins reveals a $57.84 \%$ identity between OsAsp 1 and nucellin, and a $48.27 \%$ identity between 0 sAsp 1 and nucellin-like. This indicates that nucellin is the likely orthologue of OsAsp1 not the nucellin-like that is co-expressed with Btr-like genes. While sharing homology, nucellin and nucellin-like are also only $48.97 \%$ similar, suggesting that nucellin-like may exhibit a diverged function compare to nucellin.

\section{Potential biological processes involving BTR-LIKE proteins}

The potential biological pathway of the Btr-like gene pair can be elucidated based on the strong correlation of expression between Btr-like genes and the three barley orthologues of TDR, OsPUB73 and OsINP1. These three genes are all attributed to pollen and pollen wall development. The other three genes, OsYABBY7, OsAsp1 and ITPK5, do not have sufficient information to analyse further and would require further research.

The tapetum directly surrounds the developing pollen. However, throughout meiosis, a callose wall is constructed between the meiocytes and the tapetum, preventing nutrient flow (Fernández 2012). In the late tetrad stage, the tapetum begins releasing callase enzymes to break down the callose wall and starts excreting precursors to the pollen wall (Ünal et al. 2013). Callose and cellulose are polysaccharides that are constituent components of the plant cell walls, although callose is less abundant than cellulose (Ünal et al. 2013). The timing of callose and callase secretion has been tied to male sterility in Petunia hybrida and sorghum, indicating that tight regulation of these processes is imperative to the successful creation of fertile pollen (Ünal et al. 2013). A hypothesis exists that the callose wall also acts as a template for the primexine layer in the developing pollen (Ünal et al. 2013; Waterkeyn and Bienfait 1970). This suggests that any disruption with this biological process will likely result in pollen coat abnormalities. 
While barley and wheat are closely synchronized in their developmental staging throughout anthesis, slight deviations exist between rice and barley/wheat regulating programmed cell death of the tapetum (Browne et al. 2018). The tapetum degenerates slightly earlier in rice than in barley and wheat, which commences between the late tetrad stage and early young microspore stage (Browne et al. 2018; Lazarova 2003).

The Btr-like genes are likely associated with the cell wall. This is because of the closely related Btrgenes (Btr1 and Btr2) which appear to modulate the thickness of the cell wall to form an abscission zone for easy rachis disarticulation at maturity in the spike (Pourkheirandish et al. 2015). The wheat orthologue of the Btr1 gene has been linked to the reduction in cell wall biosynthesis, which is consistent with the role of callase and callose secretion by the tapetum (Zhao et al. 2019).

Additionally, the stages of expression for Btrand Btr-like genes are overlapping where Btrgenes express in the rachis when spikes are at the beginning of white anther stage and anthers are around $1 \mathrm{~mm}$ long (Pourkheirandish et al. 2015). This further suggests that neofunctionalization between Btrand Btr-like pairs is the result of spatial expression divergence.

Based on this evidence we have deduced two working hypotheses that indicate the Btr-like genes play a role in pollen development. Our first hypothesis is that Btr1-like and Btr2-like gene products may be found in the tapetal cell wall membrane facing the locule where they regulate the secretion of callose (meiosis stage) and/or the production of callase (late tetrad and beyond). This is consistent with the biological effects of TDR and OSPUB73. We speculate that Btr and Btr-like genes perform a similar molecular function that controls the development of cell wall thickness but in a different tissue.

The alternative hypothesis is that the BTR1-LIKE and BTR2-LIKE proteins are present within the cell membrane of the meiocyte, where they could be involved in the construction of the primexine throughout the tetrad phase. This is more consistent with the function of Os/NP1 where the meiocyte alone is the location of cell wall abnormalities (i.e., the absence of the pollen aperture) (Zhang et al. 2020). This theory is also supported by the Btrgenes' predicted function in cell wall biosynthesis (Zhao et al. 2019). As the exine layer is a biological cell wall, the Btr-like genes may operate similarly in its construction. Both of these hypotheses require further investigation, an in-situ hybridization of Btr-like transcripts would provide clarity and demonstrate the exact location of Btr-like expression within the anther.

\section{Conclusions And Greater Context}

This study provides groundwork for a model of evolution of grain dispersal in barley, which can be applied to wheat, rye, and other members of Triticeae that develop a brittle rachis. Btr genes are involved in grain dispersal via cell wall modification. The Btr-like genes, which are the ancestral copies of Btrgenes, are likely involved in cell wall modification albeit in a completely different physical location. We postulate that barley grain dispersal evolved via duplication and neo-functionalization resulting from altered spatial expression patterns. The ancestral Btr-like genes are expressed in meiocytes and likely contribute to pollen development, while Btrgenes are expressed in spikes internodes and are involved in grain disarticulation. We demonstrate here that genetic processes critical to the advent of barley domestication, those being the evolution of a brittle rachis, will likely be crucial to future efforts to domesticate other wild cereals within the Triticeae tribe.

\section{Declarations}

Author Contribution statement: MP conceived the project. MP and AG designed research. AC and JL performed research. RW provided the unpublished RNAseq data. All authors wrote the paper.

\section{Acknowledgements}

MP acknowledges funding support from the Rutherford Fellowship, Commonwealth, UK, and Prof. Clair Halpin from the University of Dundee, who facilitated the identification of the expression patterns. This work is partly supported by the School of Agriculture and Food at the University of Melbourne to MP.

\section{Conflict of interest}

On behalf of all authors, the corresponding author states that there is no conflict of interest.

\section{References}

1. Barakate A, Orr J, Schreiber M, Colas I, Lewandowska D, McCallum N, Macaulay M, Morris J, Arrieta M, Hedley PE (2020) Time-resolved transcriptome of barley anthers and meiocytes reveals robust and largely stable gene expression changes at meiosis entry. bioRxiv

2. Bi X, Khush GS, Bennett J (2005) The Rice Nucellin Gene Ortholog OsAsp1 Encodes an Active Aspartic Protease Without a Plant-specific Insert and is Strongly Expressed in Early Embryo. Plant Cell Physiol 46:87-98

3. Blackmore S, Barnes SH (1985) Cosmos pollen ontogeny: a scanning electron microscope study. Protoplasma 126:91-99

Page 12/18 
4. Browne RG, lacuone S, Li SF, Dolferus R, Parish RW (2018) Anther Morphological Development and Stage Determination in Triticum aestivum. Frontiers in Plant Science 9

5. Cantalapiedra CP, García-Pereira MJ, Gracia MP, Igartua E, Casas AM, Contreras-Moreira B (2017) Large differences in gene expression responses to drought and heat stress between elite barley cultivar Scarlett and a Spanish landrace. Frontiers in plant science 8:647

6. Cao S, Guo M, Wang C, Xu W, Shi T, Tong G, Zhen C, Cheng H, Yang C, Elsheery NI (2019) Genome-wide characterization of aspartic protease (AP) gene family in Populus trichocarpa and identification of the potential PtAPs involved in wood formation. BMC plant biology 19:1-17

7. Chen F, Foolad MR (1997) Molecular organization of a gene in barley which encodes a protein similar to aspartic protease and its specific expression in nucellar cells during degeneration. Plant molecular biology 35:821-831

8. Chen L, Deng R, Liu G, Jin J, Wu J, Liu X (2019) Cytological and transcriptome analyses reveal OsPUB73 defect affects the gene expression associated with tapetum or pollen exine abnormality in rice. BMC Plant Biol 19:546

9. Du H, Liu L, You L, Yang M, He Y, Li X, Xiong L (2011) Characterization of an inositol 1, 3, 4-trisphosphate 5/6-kinase gene that is essential for drought and salt stress responses in rice. Plant molecular biology 77:547-563

10. Echlin P, Godwin H (1968) The ultrastructure and ontogeny of pollen in Helleborus Foetidus L: I. The development of the tapetum and ubisch bodies. J Cell Sci 3:161-174

11. Edlund AF, Swanson R, Preuss D (2004) Pollen and stigma structure and function: the role of diversity in pollination. Plant Cell 16:S84-S97

12. Fawaz MV, Topper ME, Firestine SM (2011) The ATP-grasp enzymes. Bioorg Chem 39:185-191

13. Fernández J (2012) Anther and pollen development in barley. University of Nottingham

14. Golicz AA, Bhalla PL, Singh MB (2018) MCRiceRepGP: a framework for the identification of genes associated with sexual reproduction in rice. Plant J 96:188-202

15. Götz S, García-Gómez JM, Terol J, Williams TD, Nagaraj SH, Nueda MJ, Robles M, Talón M, Dopazo J, Conesa A (2008) High-throughput functional annotation and data mining with the Blast2GO suite. Nucleic acids research 36:3420-3435

16. Harlan JR, Zohary D (1966) Distribution of wild wheats and barley. Science 153:1074-1080

17. Kim D, Paggi JM, Park C, Bennett C, Salzberg SL (2019) Graph-based genome alignment and genotyping with HISAT2 and HISAT-genotype. Nature biotechnology 37:907-915

18. Lazarova N (2003) Ultrastructure and function of barley anther tapetum. Comptes Rendus de l'Academie Bulgare des Sciences 56:3: 81

19. Li N, Zhang D-S, Liu H-S, Yin C-S, Li X-x, Liang W-q, Yuan Z, Xu B, Chu H-W, Wang J, Wen T-Q, Huang H, Luo D, Ma H, Zhang D-B (2006a) The Rice Tapetum Degeneration Retardation Gene Is Required for Tapetum Degradation and Anther Development. The Plant Cell 18:2999-3014

20. Li Y-Y, Yu H, Guo Z-M, Guo T-Q, Tu K, Li Y-X (2006b) Systematic analysis of head-to-head gene organization: evolutionary conservation and potential biological relevance. PLoS Comput Biol 2:e74-e74

21. Liew LC, Narsai R, Wang Y, Berkowitz O, Whelan J, Lewsey MG (2020) Temporal tissue-specific regulation of transcriptomes during barley (Hordeum vulgare) seed germination. Plant J 101:700-715

22. Mascher M (2019) Pseudomolecules and annotation of the second version of the reference genome sequence assembly of barley cv. Morex [Morex V2]. e!DAL - Plant Genomics and Phenomics Research Data Repository (PGP), IPK Gatersleben, Seeland OT Gatersleben, Corrensstraße 3, 06466, Germany

23. Mayer KF, Martis M, Hedley PE, Šimková H, Liu H, Morris JA, Steuernagel B, Taudien S, Roessner S, Gundlach H (2011) Unlocking the barley genome by chromosomal and comparative genomics. Plant Cell 23:1249-1263

24. Middleton CP, Senerchia N, Stein N, Akhunov ED, Keller B, Wicker T, Kilian B (2014) Sequencing of chloroplast genomes from wheat, barley, rye and their relatives provides a detailed insight into the evolution of the Triticeae tribe. PLoS One 9:e85761

25. Milne L, Bayer M, Rapazote-Flores P, Mayer CD, Waugh R, Simpson CG (2021) EORNA, a barley gene and transcript abundance database. Sci Data 8:90

26. Ouyang S, Zhu W, Hamilton J, Lin H, Campbell M, Childs K, Thibaud-Nissen F, Malek RL, Lee Y, Zheng L, Orvis J, Haas B, Wortman J, Buell CR (2007) The TIGR Rice Genome Annotation Resource: improvements and new features. Nucleic Acids Res 35:D883-D887

27. Pacak A, Barciszewska-Pacak M, Swida-Barteczka A, Kruszka K, Sega P, Milanowska K, Jakobsen I, Jarmolowski A, Szweykowska-Kulinska Z (2016) Heat stress affects pi-related genes expression and inorganic phosphate deposition/accumulation in barley. Frontiers in plant science 7:926

28. Pourkheirandish M, Dai F, Sakuma S, Kanamori H, Distelfeld A, Willcox G, Kawahara T, Matsumoto T, Kilian B, Komatsuda T (2017) On the Origin of the Non-brittle Rachis Trait of Domesticated Einkorn Wheat. Front Plant Sci 8:2031

29. Pourkheirandish M, Hensel G, Kilian B, Senthil N, Chen G, Sameri M, Azhaguvel P, Sakuma S, Dhanagond S, Sharma R, Mascher M, Himmelbach A, Gottwald S, Nair SK, Tagiri A, Yukuhiro F, Nagamura Y, Kanamori H, Matsumoto T, Willcox G, Middleton CP, Wicker T, Walther 
A, Waugh R, Fincher GB, Stein N, Kumlehn J, Sato K, Komatsuda T (2015) Evolution of the Grain Dispersal System in Barley. Cell 162:527539

30. Pourkheirandish M, Kanamori H, Wu J, Sakuma S, Blattner FR, Komatsuda T (2018) Elucidation of the origin of 'agriocrithon' based on domestication genes questions the hypothesis that Tibet is one of the centers of barley domestication. Plant $\mathrm{J} 94: 525-534$

31. Sakuma S, Salomon B, Komatsuda T (2011) The domestication syndrome genes responsible for the major changes in plant form in the Triticeae crops. Plant cell physiology 52:738-749

32. Tanno K-i, Willcox G (2006) How fast was wild wheat domesticated? Science 311:1886-1886

33. Toriba T, Harada K, Takamura A, Nakamura H, Ichikawa H, Suzaki T, Hirano H-Y (2007) Molecular characterization the YABBY gene family in Oryza sativa and expression analysis of OsYABBY1. Mol Genet Genomics 277:457-468

34. Ubisch Gv (1915) Analyse eines Falles von Bastardatavismus und Faktoren-koppelung bei Gerste. Zeitschrift für induktive Abstammungsund Vererbungslehre 14:226-237

35. Ünal M, Vardar F, Aytürk Ö (2013) Callose in plant sexual reproduction. Current progress in biological research. IntechOpen

36. Vera Alvarez R, Pongor LS, Mariño-Ramírez L, Landsman D (2019) TPMCalculator: one-step software to quantify mRNA abundance of genomic features. Bioinformatics 35:1960-1962

37. Waterkeyn L, Bienfait A (1970) On a possible function of the callosic special wall in Ipomoea purpurea (L) Roth. Grana 10:13-20

38. Yao W, Li G, Yu Y, Ouyang Y (2017) funRiceGenes dataset for comprehensive understanding and application of rice functional genes. GigaScience 7

39. Zeng LR, Park CH, Venu RC, Gough J, Wang GL (2008) Classification, expression pattern, and E3 ligase activity assay of rice U-boxcontaining proteins. Mol Plant 1:800-815

40. Zeng X, Mishina K, Jia J, Distelfeld A, Maughan PJ, Kikuchi S, Sassa H, Komatsuda T (2020) The Brittle Rachis Trait in Species Belonging to the Triticeae and Its Controlling Genes Btr1 and Btr2. Frontiers in Plant Science 11

41. Zhang D-S, Liang W-Q, Yuan Z, Li N, Shi J, Wang J, Liu Y-M, Yu W-J, Zhang D-B (2008) Tapetum degeneration retardation is critical for aliphatic metabolism and gene regulation during rice pollen development. Mol Plant 1:599-610

42. Zhang X, Zhao G, Tan Q, Yuan H, Betts N, Zhu L, Zhang D, Liang W (2020) Rice pollen aperture formation is regulated by the interplay between OsINP1 and OsDAF1. Nature plants 6:394-403

43. Zhao Y, Liu C, Ge D, Yan M, Ren Y, Huang X, Yuan Z (2020) Genome-wide identification and expression of YABBY genes family during flower development in Punica granatum L. Gene 752:144784

44. Zhao Y, Xie P, Guan P, Wang Y, Li Y, Yu K, Xin M, Hu Z, Yao Y, Ni Z, Sun Q, Xie C, Peng H (2019) Btr1-A Induces Grain Shattering and Affects Spike Morphology and Yield-Related Traits in Wheat. Plant Cell Physiol 60:1342-1353

\section{Supplemental Data}

Supplementary Data 6 and 7 are not available with this version.

\section{Figures}


A

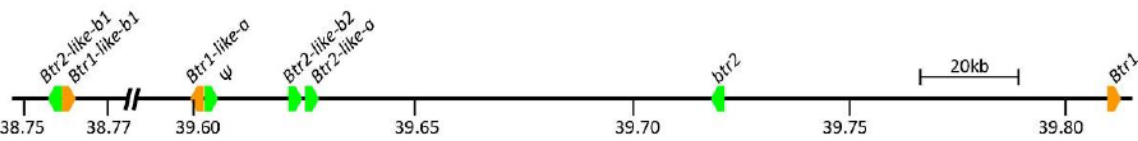

B

\begin{tabular}{|c|c|}
\hline BTR1 & MAQPPQWKAMYQYVTRRAHDGCARVEESVAAARGALATP-MVLDTRDAAGRCTLLHSAVT \\
\hline BTR1-LIKE-b1 & MAQPAGWKAMYQQVVIEADGSCADVEHRVAAARTALESPEAVLTSRDPTGVYTLLKSALD \\
\hline \multirow[t]{2}{*}{ BTR1-LIKE-a } & MAQPAGWKAMYQQVVIEADGSCADVEHRVAAARTALESPEAVLTSRDPTGVYTLLKSALD \\
\hline & 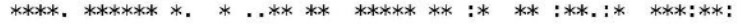 \\
\hline BTR1 & HVEHASDCLSGFIVSVVVAELLVLHGCGAVPSRPVASIDGLRRNRDD-HDEWLALSRLEA \\
\hline BTR1-LIKE-b1 & DVEQASDSLSAFIIHAVAAERLALHGCGVIPSQPVARIADLRDDHHDRHDERLALNRLED \\
\hline \multirow[t]{2}{*}{ BTR1-LIKE-a } & NVEQASDSLSAFIIHAVAAERLALHGCGPIPSQPVARIADLRDDHHDRHDERLALNRLED \\
\hline & $* *: * * *, * *, * *:, * * * * *, * * * * *: * *, * * * *, * * *: . * * * * *, * * *, * * *$ \\
\hline BTR1 & AREHGQDALRGVEGAFTLLASVRFMLRSRTPDAAGRRQAMEEQLHAAAVELQAVVGSVAN \\
\hline BTR1-LIKE-b1 & ARDFAKRALRGVDGALKLLGSVQYMLRDLGAGAAGRRQAMKEQLQAAARELQLVAVSVCN \\
\hline \multirow[t]{2}{*}{ BTR1-LIKE-a } & ARDFAKRALRGVDGALKLLGSVQYMLRDLGAGAAGRRQAMKEQLQAAARELQLVAVSVCN \\
\hline & **:..: $: * * * * *: * *: . * *, * * .: * * * . \quad \ldots * * * * * * * *: * * *: * * *$ * $* * * * ., * *, *$ \\
\hline BTR1 & MSALAFLATQPAIRNRIQ \\
\hline BTR1-LIKE-b1 & TRSLARMATEPPIGNRVQ \\
\hline \multirow{2}{*}{ BTR1-LIKE-a } & TRSLARMATEPPIGQ--- \\
\hline & $: * *: * *: * . *$ : \\
\hline
\end{tabular}

C

BTR2 MEVWRKTAAEASARSLTYINATN-AVVEAIMAARQRYALASEDCRRFRPGVHPPPNAGQG BTR2-LIKE-a MAEWMNLALAAAFDSFAYTETN--GVAEAVAGAIQQYRLAAEECRGIGQGVHPTPNAGQG BTR2-LIKE-b1 MEEWRNLALAAAGESLANTMTRHMGVAEAIARAGQRYRLAAEECRGFGQGVHPTPNAGER BTR2-LIKE-b2 MEEWRNLALAAADESFANTVTN--GVAETIASAIQQYRLAAEECRGFGQGVHPTPNAGER

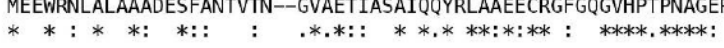

BTR2 ASAGGDFVELAIDRIKRFSRFQAVLGNVFSLCAAPARIGLQVQGNAPWWRHRWQLHHADA BTR2-LIKE-a ASAGGDSIDLALTRIKSITRFHAVRGSVFSVCV--RRMGL--QPDTP-----WRLQHATA BTR2-LIKE-b1 ASAGGDFVDLAIDRIKSISRFHAVRGSVFSLCV--RRIGL--0GIGL---_----HGDE BTR2-LIKE-b2 ASAGGDFVDLAIDRIKSISRFHAVRGSVFSLCV--RRIGL--QGNALWY--MWQFYHADE

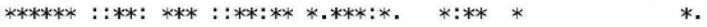

\begin{tabular}{|c|c|}
\hline $\begin{array}{l}\text { BTR2 } \\
\text { BTR2-LIKE-a } \\
\text { BTR2-LIKE-b1 } \\
\text { BTR2-LIKE-b2 }\end{array}$ & $\begin{array}{l}\text { AHHAETALHCLHSAKSHGHAALGVFHVMLRPPSPRALAHAWAPAAEQLLRRVMDDLAMAE } \\
\text { ARHAEMAIRCLGTAKSYGHAALSVFHRMLRPPSPQAVARAWAPAAELLLRRAIVNLDMAE } \\
\text { ARHAETAMLSLRSAKSHGHAALRVFERMLRPPSPQAVARAWAPAAEQLLRRAINNLDMAA } \\
\text { ARHAETAMLSLRSAKSHGHAAVRVFERMLRPPSPQAVARAWAPAAVQLLRRAIKNLAMAE } \\
* . * * * *: . *: * * *: * * * *: * * * * * * * * * * * * * * * * * * * * *: * * *\end{array}$ \\
\hline $\begin{array}{l}\text { BTR2 } \\
\text { BTR2-LIKE-a } \\
\text { BTR2-LIKE-b1 } \\
\text { BTR2-LIKE-b2 }\end{array}$ & $\begin{array}{l}\text { AAVDRMRPAIVAQFFDASMLLHG }-- \\
\text { ASVGKIRPAIGVEYNDARRLLHG-- } \\
\text { ASVGRIRPAIVVEYKYARKLLNASI } \\
\text { VSVGQIRPAIVVEYNDARRLLHG-- } \\
.: * . .: * * * * .:: * * * *: .\end{array}$ \\
\hline
\end{tabular}

\section{Figure 1}

(A) The genetic map of chromosome $3 \mathrm{H}$ of cv. Morex (Pseudomolecules V2 annotation). Orange colour indicates sequences showing homology with the Btr1 gene, green colour indicates sequences showing homology with the Btr2 gene. $\Psi$ indicates a pseudogene. (B and C) Amino acid sequence alignment for copies of the Btr-like and Btr genes on chromosome 3H. (B) BTR1: HORVU.MOREX.r2.3HG0195510, BTR1-LIKE-a: HORVU.MOREX.r2.3HG0195460, BTR1-LIKE-b1: HORVU.MOREX.r2.3HG0195170 (C) BTR2: NCBI Genbank: KR813335.1 (OUH602), BTR2-LIKE-a: HORVU.MOREX.r2.3HG0195480, BTR2-LIKE-b1: HORVU.MOREX.r2.3HG0195160, BTR2-LIKE-b2: HORVU.MOREX.r2.3HG0195470. 
A

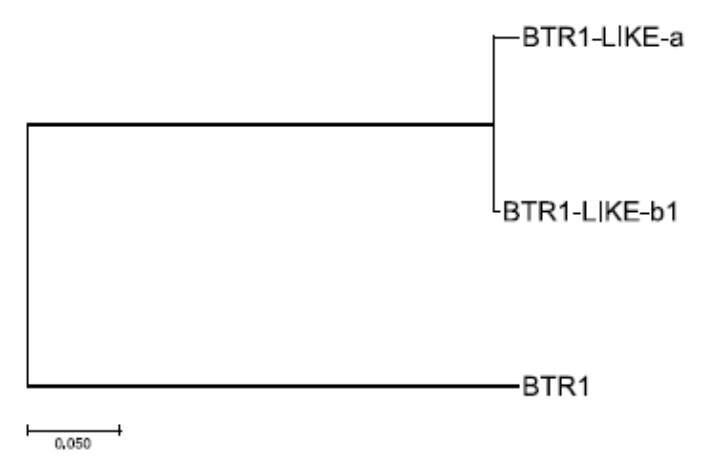

B

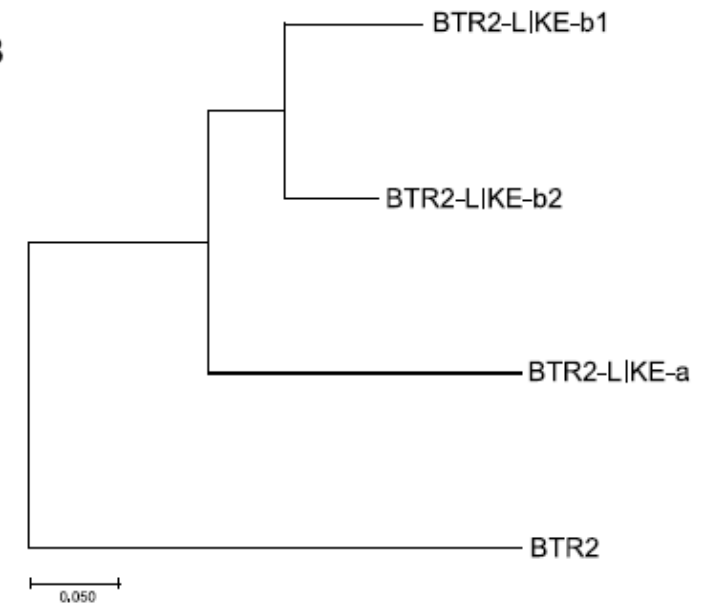

Figure 2

Evolutionary analysis of Btr and Btr-like genes. (A) Analysis of BTR1 and BTR1-LIKE proteins. (B) Analysis of BTR2 and BTR2-LIKE proteins. The evolutionary history was inferred using the Neighbor-Joining method. The evolutionary distances are in the units of the number of amino acid substitutions per site. Evolutionary analyses were conducted in MEGA X.

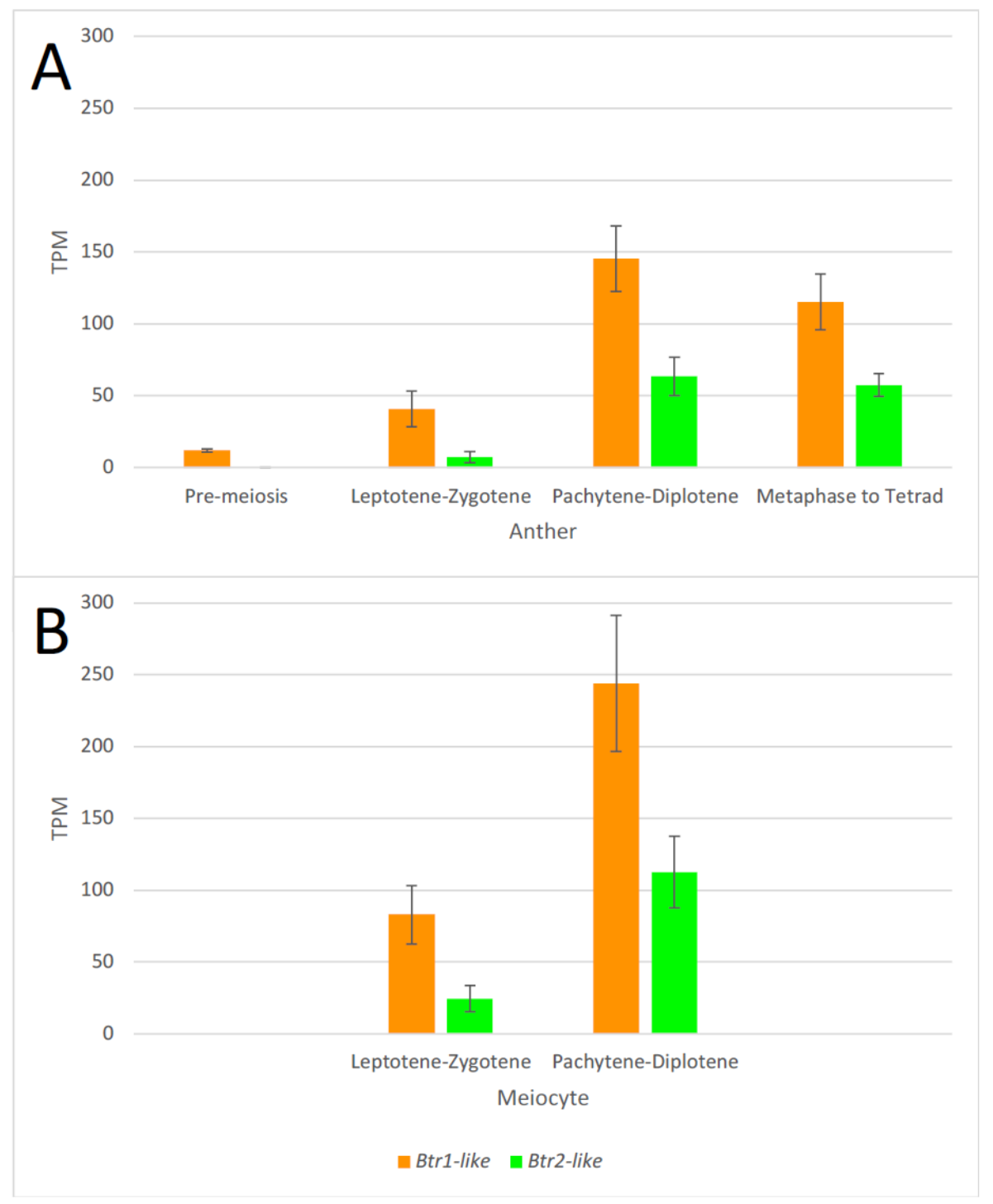

Figure 3 
Gene expression of Btr1-like-a (orange) and Btr2-like-a (green) during meiosis of the male gametophyte (PRJNA558196) in the A: anther and B: meiocyte. Three biological samples $(n=3)$ across all stages. The TPM values for replicates were averaged to represent each sample. Error bars correspond to standard error.

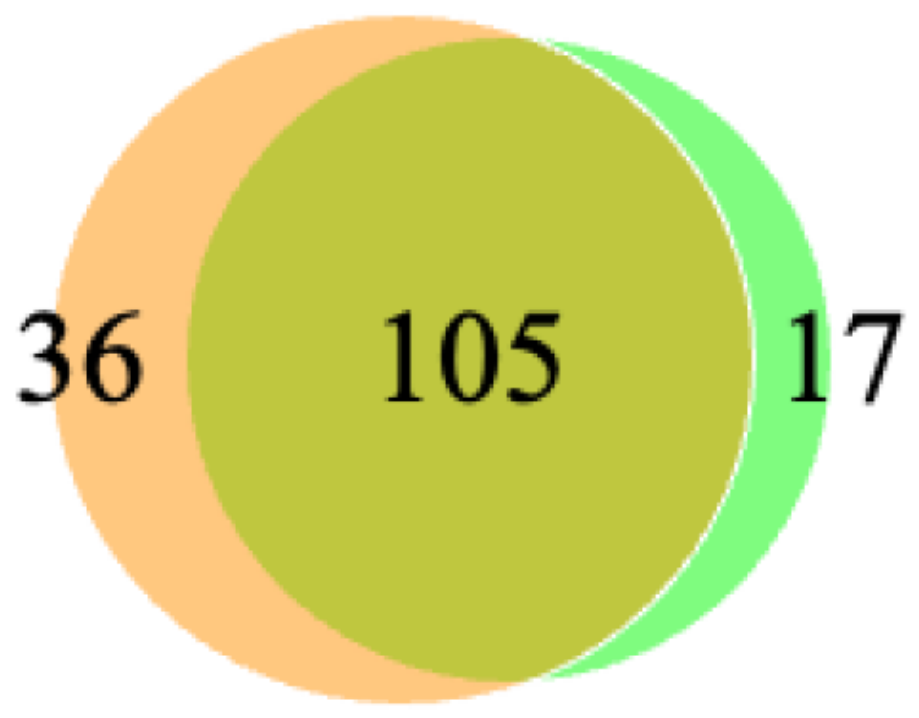

\section{Figure 4}

Venn diagram showing the distribution of genes co-expressed with more than 0.95 Pearson's correlation with Btr1-like (orange) and Btr2-like (green), and the overlap between both.

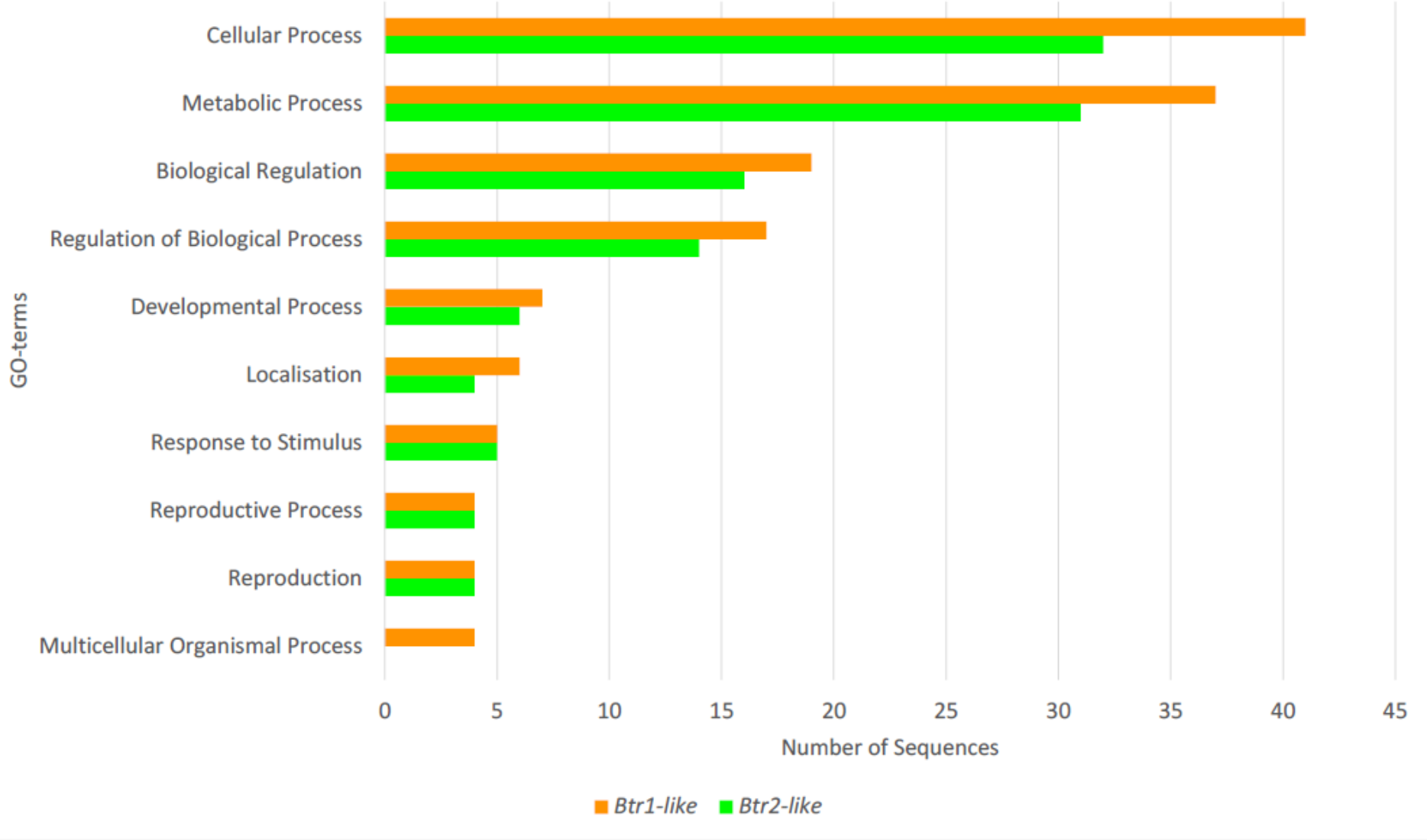

\section{Figure 5}

GO analysis of the 'biological process' category for genes co-expressed with Btr1-like (orange) and Btr2-like (green).

\section{Supplementary Files}


This is a list of supplementary files associated with this preprint. Click to download.

- SupplementaryData1.csv

- SupplementaryData2.csv

- SupplementaryData3.xlsx

- SupplementaryData4.docx

- SupplementaryData5.xIsx 